\title{
Intranodal Capillary-Cavernous Hemangioma- An Uncommon Histopathological Lesion
}

\section{Ramesh Oswal ${ }^{1}$, Sunil V Jagtap ${ }^{2}$, Snigdha A Vartak $^{3}$, Swati S. Jagtap ${ }^{4}$, Savita Oswal ${ }^{5}$}

${ }^{1}$ Associate Professor, Department of Pathology, Krishna Institute of Medical Sciences Deemed University, Karad, India.

${ }^{2}$ Professor, Department of Pathology, Krishna Institute of Medical Sciences Deemed University, Karad, India. ${ }^{3}$ Assistant Lecturer, Department of Pathology, Krishna Institute of Medical Sciences Deemed University, Karad, India.

${ }^{4}$ Associate Professor, Department of Physiology, Krishna Institute of Medical Sciences Deemed University, Karad, India.

${ }^{5} \mathrm{CMO}$, Krishna Institute of Medical Sciences Deemed University, Karad, India.

\begin{abstract}
A 35 year female presented with gradually increasing swelling in inguinal region of 8 years which was painful during menses. On systemic examination no significant disease was noted. On local examination right inguinal region showed soft tissue nodular mass measuring $3 \times 1.5 \times 1 \mathrm{~cm}$.On ultrasonography showed soft tissue nodule suggestive of vascular lesion. Minimal pericapsulitis was noted .No abscess or necrosis was noted. Lesion was surgically excised and sent for histopathology. Grossly received single oval lymph node measuring $2.5 \times 2 \times 1 \mathrm{~cm}$. Cut section was dark grey brown with areas of hemorrhages. On histopathology diagnosed as Capillary Cavernous Hemangioma of right inguinal lymph node. We are presenting this case for its extreme rarity, its clinical, radiological, histopathological presentation. Recognizing these vascular lesion entities in lymph node is essential to for diagnosis and to guide therapy.
\end{abstract}

Keywords: Intranodal tumor, Inguinal lymphadenopathy, Nodal hemangioma

\section{INTRODUCTION}

The vascular tumors and tumor like conditions of the lymph node include Capillary Cavernous Hemangioma $(\mathrm{CCH})$, bacillary angiomatosis, lymphangioma and vascular transformation of the sinuses. Hemangioma involving lymph node is extremely rare ${ }^{[1,2]} \mathrm{CCH}$ of the lymph node is extremely rare. Only 18 cases of $\mathrm{CCH}$ have been reported in the English language medical literature, to our knowledge. ${ }^{[3]}$ In our case patient had clinically symptomatic painful nodule of long duration. On histopathology finding it was diagnosed as $\mathrm{CCH}$ of the lymph node.

\section{CASE REPORT}

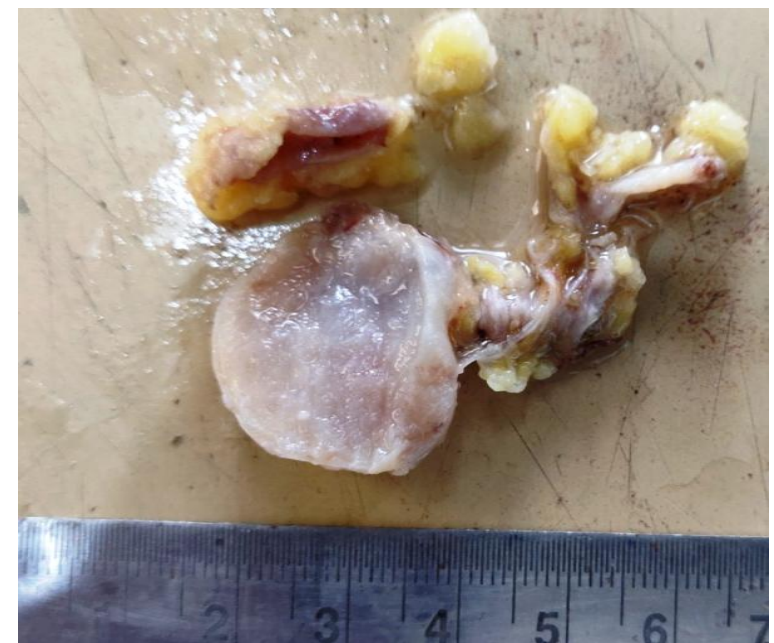

Figure:1 gross specimen cut section of lymph node. 
A 35 year female presented with gradually increasing swelling in inguinal region of 8 years. She gave history of swelling which was painful during menses. On systemic examination no significant disease was noted. Patient had no history of trauma, no any systemic infection. Her HIV status was negative. Local right inguinal region showed soft tissue nodular mass, measuring $3 \times 1.5 \times 1 \mathrm{~cm}$.
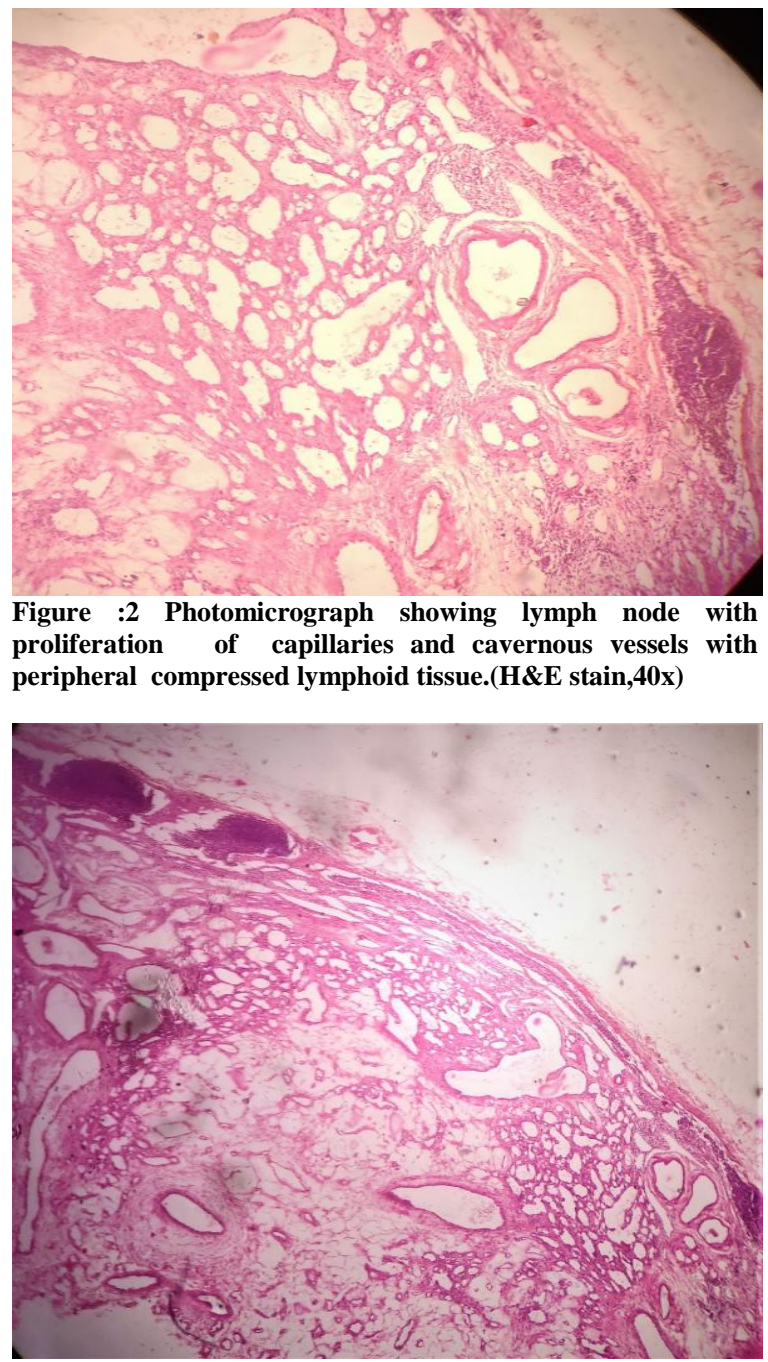

Figure: 3 Photomicrograph showing lymph node with proliferation of capillaries and cavernous vessels, lined by endothelium and lumen filled with RBCs. The peripheral compressed lymphoid tissue is noted.(H\&E stain,40x)

On ultrasonography, soft tissue nodule suggestive of vascular lesion was reported. Minimal pericapsulitis was evident. No abscess or necrosis was noted. On physical examination a single, tender, mobile, well defined right inguinal adenopathy was noted. On histopathology we received single encapsulated oval lymph node measuring $2.5 \times 2 \times 1 \mathrm{~cm}$. (fig.-1) Cut section grey brown with focal areas of haemorrhages. On microscopy there were proliferation of dilated capillaries and cavernous vessels. At the periphery compressed lymphoid tissue with fibrosed thick capsule was noted. The capillaries were lined by endothelial cells and lumen were filled with RBCs. (Fig-2, 3). On histopathology diagnosed as Capillary Cavernus Hemangioma of right inguinal lymph node.

\section{DISCUSSION}

The various types of vascular proliferation may occur in lymph nodes, but hemangiomas in lymph nodes are extremely rare. The hemangiomas are common in skin mucosa and soft tissue, but the occurrence in lymph node is extremely rare ${ }^{[4]}$ The $\mathrm{CCH}$ is still extremely rare type of lesion in lymph node. Intranodal hemangiomas present as an asymptomatic, solitary palpable lymph node. They may be an incidental finding. Clinically these lesions are non regressive. The may present with bleeding, secondary infections, hormonal changes or painful swelling. In our case the lesion was painful during menses.

The reported age group affected for $\mathrm{CCH}$ is 11- 75 years with mean age of 53 years. The size of the involved lymph nodes ranges from 0.2 to $3.5 \mathrm{~cm}$. ${ }^{[5]}$

Intranodal hemangiomas have also been found in association with other vascular lesions, such as intestinal angiodysplasia and oral hemangiopericytoma. ${ }^{[6]}$ For superficial $\mathrm{CCH}$, sonography can show calcifications and heterogeneity, and with color Doppler shows enhanced hypervascularization. ${ }^{[7]}$ Nowdays with improvements of imaging techniques like enhanced MRI it can be differentiated from other vascular lesions.

It is best diagnosed on histopathology, showing a proliferation of capillaries and cavernous vessels filled with erythrocytes and lined by endothelial cells.

On histology various types are recognized- lobular capillary, cellular, 
epitheliod and capillary cavernous. ${ }^{[8]} \mathrm{CCH}$ is more centered in lymph node hilum or medulla with well preserved nodal parenchyma. In our case the mass of closely packed capillaries or cavernous vessels lined by flat endothelial cells was noted. The lumen was filled with blood. The vascular lesion extends from the subcapsular sinuses through to the medulla of the lymph node.

Various vascular lesion and malignancy can be evoked as a differential diagnosis of intranodal $\mathrm{CCH}$ are tumour like vascular lesions are lobular hemangioma, vascular epitheiloid tumor, lymphangioma and hamartoma while malignant lesions are hemangioendothelioma, Kaposi sarcoma and angiosarcoma. ${ }^{[1,9]}$

In the lymphangioma of the lymph nodes will show prominent lymphatic vessels with lymph. In vascular transformation of lymph node sinuses is characterized by the entire lymph node architecture effaced and replaced by the vascular proliferation, obstruction, and often with fibrosis. ${ }^{[10]}$

While in bacillary angiomatosis shows lobular proliferation of capillaries with ectatic vessels lined by prominent endothelial cells in edematous stroma with polymorms, lymphocytes and histiocytes. It has microorganisms and Warthin-Starry special stain will highlight Bartonella organisms. It commonly affects immunocompromised individuals.

In cases of epithelioid hemangioendothelioma it will shows sheets and cords of plump spindle cells with nuclear pleomorphism and abundant eosinophilic cytoplasm with vacuoles occasionally containing erythrocytes, set in a myxohyaline stroma. It localization is more commonly in soft tissue, bones than in lymph nodes.

The angiomyomatous hamartoma, has been reported in inguinal lymph nodes. It starts in the hilum of the node and the parenchyma is replaced by blood vessels, fat, smooth muscle, and fibrous tissue without cellular fascicle formation.
The mixed types can easily mimic malignancies and their recognition is of importance. The malignant condition like Kaposi sarcoma should be excluded. Kaposi sarcoma shows curved fascicles of spindle cells separated by slit-like vascular spaces with extravasated red blood cells and frequent mitotic figures extravasated erythrocytes, hemosiderin, and plasma cells.

While in angiosarcoma it will show infiltrative vascular channels, usually with marked nuclear atypia.

IHC of this tumor are positive for endothelial cells for CD 31 and CD34 and factor VIII related antigen and negative for epithelial marker pancytokeratin and lymphatic marker D2-40.

The surgical excision of lesion is choice of treatment. Other modalities of treatment are chemical or thermic sclerotherapy, pulse dye laserbare currently being used. [11] The importance of identifying these entities is to avoid misdiagnosing them as malignant vascular tumors. In our case surgical excision was done and patient is advised regular follow up. She responded well to treatment.

\section{CONCLUSION}

The vascular tumors and tumor-like conditions of the lymph nodes are rare. We present an extremely rare case $\mathrm{CCH}$ of the lymph node. Recognizing the importance these entities of complex vascular malformation in lymph node is essential to for diagnosis to avoid misdiagnosing them as malignant vascular tumors, to guide therapy and follow up.

\section{Acknowledgement: None}

\section{Conflict of Interest: None}

\section{Source of Funding: None}

\section{REFERENCES}

1. Rosai J. Vascular tumors and tumorlike conditions of lymph node. In: Rosai J, editor. Rosai and Ackermann's Surgical 
Pathology. Ninth Edition. New York: Mosby; 2004. pp. 1969-1971.

2. Har-El G, Heffner DK, Ruffy M. Haemangioma in a cervical lymph node. $\mathrm{J}$ Laryngol Otol. 1990;104:513-515.

3. Fabio P, Camillo D. Capillary cavernous hemangioma of lymph node. Int J Surg Pathol. 2010;18:338.

4. Maha Elgoweini, Runjan Chetty- Resident Short Reviews.Primary Nodal Hemangioma.Archives of Pathology and Laboratory Medicine. 2012;136:110-12.

5. Gupta IM. Hemangioma in a lymph node. Indian J Pathol Bacteriol. 1964; 71:110-111.

6. Almagro UA, Choi H, Rouse TM. Hemangioma in a lymph node. Arch Pathol Lab Med. 1985;109:576-578.

7. Furuta T, Shimose S, Nakashima Y, Kubo $\mathrm{T}$, Ochi M. Novel sluggish speed signs on ultrasound is indicative of hemangiomas. Acta Radiol. 2017;58(10):1231-1237.

8. Tsang WY, Chan JK, Dorfman RF, Rosai J. Vasoproliferative lesions of the lymph node. Pathol Annu. 1994;29:63-133.
9. SV Jagtap, D Shukla, VS Bonde, SS Jagtap .Primary Angiosarcoma of the Breast: An Uncommon Histopathological Subtype.J Clin Diagn Res. 2015 Dec; 9,12 : ED05ED06.

10. Chan JK, Warnke RA, Dorfman R. Vascular transformation of sinuses in lymph nodes. A study of its morphological spectrum and distinction from Kaposi's sarcoma. Am J Surg Pathol. 1991;15,8 ,732-43.

11. S.Blaise, M.Charavin-Cocuzza, H. Riom, M.Brix, C.Seinturier, J.M. Diamand et al.Treatment of Low-flow Vascular Malformations by Ultrasound-guided Sclerotherapy with Polidocanol Foam: 24 Cases and Literature Review. Eur J Vasc Endovasc Surg 2011: 41, 412-417.

How to cite this article: Oswal R, Jagtap SV, Vartak SA et.al. Intranodal capillary-cavernous hemangioma- an uncommon histopathological lesion. Int J Health Sci Res. 2021; 11(4): 114117. DOI: https://doi.org/10.52403/ijhsr. 20210415 